\title{
Nuclear heating measurements by gamma and neutron thermometers
}

\author{
R. Van Nieuwenhove*, L. Vermeeren \\ SCK-CEN \\ *rvnieuwe@sckcen.be
}

\begin{abstract}
A gamma thermometer suitable for very high gamma heating levels (up to $20 \mathrm{~W} / \mathrm{g}$ ) has been designed and modelled by means of detailed finite element calculations. Based on a sensitivity analysis, the predicted accuracy of this gamma thermometer is better than $5 \%$. A novel miniaturized gamma thermometer is proposed in which a single thermocouple is used as the gamma absorption element, allowing a reduction of the sensor diameter down to $3 \mathrm{~mm}$.

Monte Carlo calculations (by MCNP) have been performed to assess the relative contribution of neutrons to the nuclear heating in a gamma thermometer. Calculations have been performed for gamma thermometers with an inner body made of various materials, such as stainless steel, tungsten, molybdenum and rhodium. By using gamma thermometers made of different materials, it will be possible to deduce the nuclear heating rates in these materials and also to separate out the neutron and gamma heating contributions. The Monte Carlo calculations show that nuclear heating of rhodium is mainly due to neutrons, converting the rhodium gamma thermometer effectively in a neutron thermometer. The sensitivities of the gamma thermometers with $\mathrm{W}$, Mo or $\mathrm{Rh}$ as heated materials have been modelled by finite element calculations. It is found that both the Mo and the Rh based sensor have a very linear response up to a nuclear heating of 20 $\mathbf{W} / \mathrm{g}$.
\end{abstract}

Keywords-Nuclear measurements, Gamma-ray detectors

\section{INTRODUCTION}

Nuclear heating measurements in material test reactors are important for various reasons. For the design of experimental rigs, a good knowledge of the gamma heating is required in order to predict the correct irradiation temperature of samples. For power calibrations of test fuels, the knowledge of the contribution of gamma heating is crucial in order to attain the required precision. For nuclear fusion, it is important to know the nuclear heating of various materials such as for tungsten, copper, graphite, chromium, etc. Discrepancies between measured and calculated gamma heating levels (such as by MCNP) have regularly been observed in the past and are partly related to imprecise nuclear data. In order to contribute to a better understanding and predictability, modified gamma thermometers (GT) containing different materials have been designed and modelled.

\section{DESCRIPTION OF THE SCK •CEN GAMMA THERMOMETER}

The basic design and principles of the gamma thermometer (GT) are described in $[1,2]$ and have been routinely produced at the Halden Reactor Project since 1962. SCK •CEN designed a slightly different version, as shown in Figure 1 .

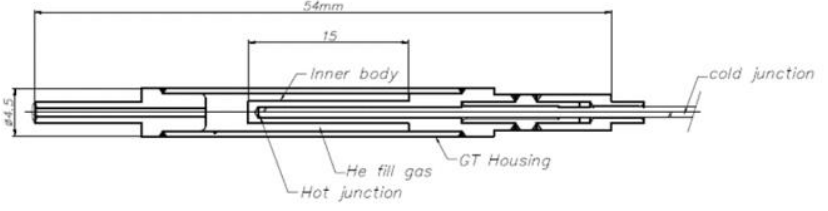

Fig. 1. Schematic drawing of the SCK $\cdot \mathrm{CEN}$ gamma thermometer.

The inner body (made of stainless steel) is heated by gamma rays and the temperature difference between the tip of the inner body and the coolant is measured by a differential thermocouple (type $\mathrm{K}$ ). The inner body (diameter $2.1 \mathrm{~mm}$ ) is thermally insulated from the outer housing by a gas layer $(0.7 \mathrm{~mm})$. The GT is sufficiently strong to be applicable under Pressurized Water Reactor (PWR) conditions. In 1996, the design was modified in order to adapt it to the higher gamma heating (up to $15 \mathrm{~W} / \mathrm{g}$ ) of the BR2 reactor (see Figure 1). The main modifications were i) reduction of the length of the inner body from $30 \mathrm{~mm}$ to $15 \mathrm{~mm}$ and ii) replacement of the xenon gas by helium. Other minor differences are that the material of the housing and inner body are made of AISI 304 for the SCK $\cdot$ CEN GT (316L in the Halden GT) and that the material of the thermocouple sheath is made in AISI 316L (Inconel 600 in the Halden GT). The reduction of the length of the inner body and the replacement of the gas by He allows to limit the temperature increase of the inner body at the highest gamma heating and to maintain a fairly linear response.

\section{FINITE ELEMENT MODELLING}

The gamma thermometer was modelled by means of the 2D finite element program QuickField. Temperature dependent material properties were obtained from the database MPDB (JAHM Software). The gas properties were obtained from the NIST website (National Institute of Standards and Technology). Radiation losses from the inner body have an

R. Van Nieuwenhove and L. Vermeeren are with the Nuclear Research Centre SCK•CEN, B-2400 Mol, Belgium (e-mail: rvnieuwe@sckcen.be, lvermeer@sckcen.be ). 
impact on the sensitivity of the GT and are taken into account. The emissivity of the polished inner body is a parameter with considerable uncertainty. Therefore, the emissivity value was adjusted such as to obtain correspondence between the calculated and the measured time constant of the GT. This resulted in an emissivity of 0.3 .

The material properties of the thermocouple require also careful consideration because the diameter of the thermocouple $(1 \mathrm{~mm})$ is relatively large compared to the diameter of the inner body $(2.1 \mathrm{~mm})$. The thickness of the sheath of the thermocouple and the diameter of the two wires (chromel and alumel) are obtained from the manufacturer. Typically, the sheath has a thickness of $0.13 \mathrm{~mm}$ while the diameter of the wires is 0.18 $0.2 \mathrm{~mm}$. The thermocouple insulation consists of compacted $\mathrm{Al}_{2} \mathrm{O}_{3}$ powder. By weighing a piece of thermocouple, the density of the $\mathrm{Al}_{2} \mathrm{O}_{3}$ powder was determined to be $2.56 \mathrm{~g} / \mathrm{cm} 3$ (considering the theoretical density of the metal), while the average density of the thermocouple was $5.885 \mathrm{~g} / \mathrm{cm}^{3}$. The thermal conductivity of the $\mathrm{Al}_{2} \mathrm{O}_{3}$ powder was taken to be $0.33 \mathrm{~W} / \mathrm{mK}$ (based on previous experience at the Halden Project), independent of the temperature. In the finite element calculations, all the other thermal conductivities were described as temperature dependent. For the 2D finite element calculations, the thermocouple (with its 2 inner wires) was modelled as a uniform element with calculated averaged density and averaged thermal conductivity and specific heat.

The temperature of all the outer surfaces of the GT were set to be equal to the coolant temperature.

\section{RESULTS}

Finite element calculations have been performed for a helium and an argon filled GT up to $20 \mathrm{~W} / \mathrm{g}$ at an outer coolant temperature of $100^{\circ} \mathrm{C}$.

The results are shown in Figure 2. It can be seen that the helium filled GT is fairly linear over the whole range while the argon-filled GT exhibits some clear nonlinearity.

In the following, we define the sensitivity of the GT as the temperature increase (as measured by the differential thermocouple) divided by the gamma heating $\mathrm{G}$ (expressed in $\mathrm{W} / \mathrm{g}$ ), i.e. $S=\Delta \mathrm{T} / \mathrm{G}$.

The sensitivity depends on the thermal conductivities of the materials, which are temperature dependent. Hence, the sensitivity depends not only on the outer coolant temperature but also on the gamma heating itself (because a higher gamma heating will result in a higher temperature of the inner body). Because the thermal conductivities generally increase with temperature, the sensitivity of the GT decreases at higher coolant temperature. A calculation has been made for the $\mathrm{He}$ filled GT at $300{ }^{\circ} \mathrm{C}$ (see Figure 2). In this case, the sensitivity is $30 \%$ lower as compared to the $100{ }^{\circ} \mathrm{C}$ case. It can also be observed that the linearity at $300{ }^{\circ} \mathrm{C}$ is even better than the linearity at $100{ }^{\circ} \mathrm{C}$. This is because the relative changes in thermal conductivities are smaller in this case.

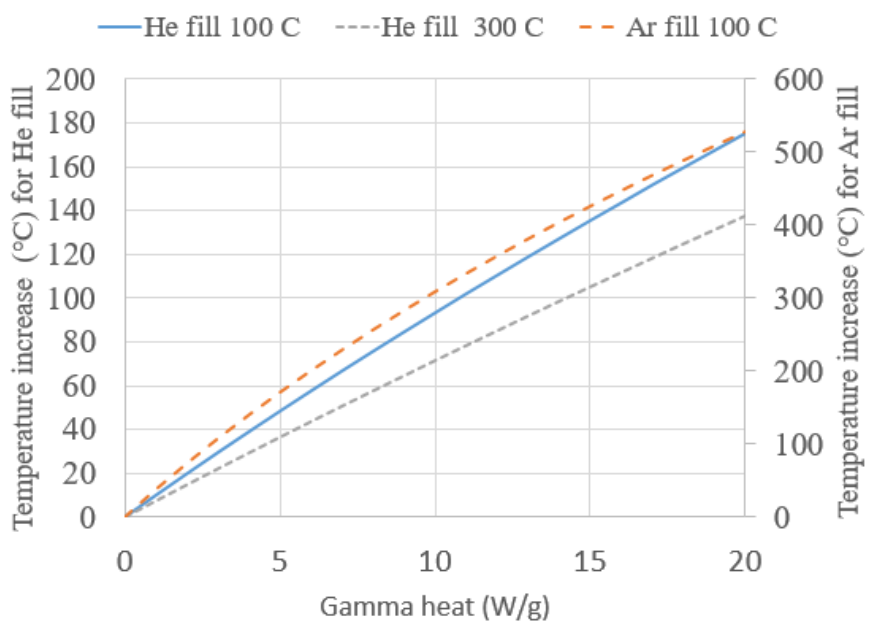

Fig. 2. Calculated temperature increase for a He-filled GT (at $100{ }^{\circ} \mathrm{C}$ and $300^{\circ} \mathrm{C}$ ) and for an Ar filled GT (at $100^{\circ} \mathrm{C}$ ).

For gamma thermometers filled with xenon or argon, the effect of radiation losses from the inner body is relatively important. However, for a GT filled with helium, the effect of radiation losses on the GT sensitivity is relatively small; $1 \%$ at an environment temperature of $100{ }^{\circ} \mathrm{C}$ (at $10 \mathrm{~W} / \mathrm{g}$ ) and $2.6 \%$ at an environment temperature of $300^{\circ} \mathrm{C}$ (at $10 \mathrm{~W} / \mathrm{g}$ ).

Using the finite element model, it is also possible to deduce the time constants of the different types of GTs. First, the temperature distribution is calculated for the case in which the thermocouple only is heated (assuming one uses the thermocouple itself as electrical heater), while keeping the outer temperature constant. Thereafter, the heating is suddenly switched off and the time evolution of the tip of the thermocouple is modelled. After some time after switch-off, the decay becomes purely exponential and this part is then fitted by an exponential function to obtain the time constant. Some results are shown in Table III.

\section{UNCERTAINTY ANALYSIS}

Because of the simple geometry of the GT and the detailed finite element modelling, it is in principle possible to determine the GT response with a very good accuracy. However, because of uncertainties in the thermal conductivities of the materials and the gasses used, as well as due to the unavoidable mechanical tolerances, uncertainties are introduced in the calculated GT sensitivity.

Based on a comparison of various data found in the open literature, we will assume the following uncertainties on the thermal conductivities: $10 \%$ on the thermal conductivity of steel (AISI 304 and AISI 316L) and $5 \%$ on the thermal conductivity of He or Ar.

For the value of the emissivity (radiation from inner body), we assume an uncertainty of $20 \%$.

For the thermal conductivity of the thermocouple, the main uncertainty is due to the thermal conductivity of the compacted $\mathrm{Al}_{2} \mathrm{O}_{3}$ powder. In the model, we assume a thermal conductivity of only $0.33 \mathrm{~W} / \mathrm{mK}$ but here we will allow for a possible 
increase of a factor 5 .

Two different types of uncertainty are considered related to the mechanical tolerances: The first is related to the diameter of the inner body, the second is related to the inner diameter of the outer tube. In the analysis, we assume an uncertainty of $50 \mu \mathrm{m}$. Both uncertainties lead to a change in the gas gap width of $7.14 \%$, as the width of the gas gap is $0.7 \mathrm{~mm}$.

Finally, we also need to consider the uncertainty of the temperature measurement itself. For thermocouples type K, with special tolerance, (ASTM E230) the uncertainty is given as $\pm 1.1{ }^{\circ} \mathrm{C}$ or $0.4 \%$ (whichever is greater). For temperatures up to $275{ }^{\circ} \mathrm{C}$, one has thus to assume an uncertainty given by $\pm 1.1^{\circ} \mathrm{C}$. The uncertainty on the sensitivity of the GT thus depends on the actual temperature increase (determined by the gamma heating). In what follows, we will calculate the total uncertainty for a He and an Ar filled GT at three different levels of gamma heating, namely at 5,10 and $15 \mathrm{~W} / \mathrm{g}$ and for a coolant temperature of $100^{\circ} \mathrm{C}$.

The total uncertainty is calculated as the root of the summed squared errors. The uncertainties for the He and Ar filled GTs are summarized respectively in Tables I and II:

TABLE I

UNCERTAINTIES FOR THE HE-FILLED GT

\begin{tabular}{ll}
\hline \hline Variation & $\begin{array}{l}\text { Resulting uncertainty in } \\
\text { sensitivity }( \pm \%)\end{array}$ \\
\hline $\begin{array}{l}\text { thermal conductivity of } \\
\text { helium by } 5 \%\end{array}$ & 4.4 \\
$\begin{array}{l}\text { Thermal conductivity of steel } \\
\text { by } 10 \%\end{array}$ & 1.0 \\
$50 \mu \mathrm{m}$ change of radius of & 0.47 \\
$\begin{array}{l}\text { inner body } \\
50 \mu \mathrm{m} \text { change of inner radius } \\
\text { of outer tube }\end{array}$ & 1.40 \\
$\begin{array}{l}\text { Thermal conductivity of } \\
\mathrm{Al}{ }_{2} \mathrm{O}_{3} \text { by factor } 5\end{array}$ & 0.14 \\
$\begin{array}{l}\text { Un change in emissivity } \\
\text { Uncertainty temperature of }\end{array}$ & 0.18 \\
$1.1{ }^{\circ} \mathrm{C}$ & $2.3 / 1.18 / 0.81$ (for 5,10, \\
Combined uncertainty & $15 \mathrm{~W} / \mathrm{g})$ \\
& $5.28 / 4.89 / 4.82$ (for 5,10, \\
\hline \hline
\end{tabular}

TABLE II

UNCERTAINTIES FOR THE AR-FILLED GT

\begin{tabular}{ll}
\hline \hline Variation & $\begin{array}{l}\text { Resulting uncertainty in } \\
\text { sensitivity }( \pm \%)\end{array}$ \\
\hline $\begin{array}{l}\text { thermal conductivity of argon } \\
\text { by } 5 \%\end{array}$ & 1.08 \\
$\begin{array}{l}\text { Thermal conductivity of steel } \\
\text { by } 10 \%\end{array}$ & 3.67 \\
50 micron change of radius of & 0.21 \\
inner body & \\
$50 \mu \mathrm{m}$ change of inner radius & 1.14 \\
of outer tube & \\
$\begin{array}{l}\text { Thermal conductivity of } \\
\mathrm{Al} 2 \mathrm{O}_{3} \text { by factor } 5\end{array}$ & 0.10 \\
$20 \%$ change in emissivity & 0.30 \\
Uncertainty temperature of & $0.65 / 0.35 / 0.25$ (for 5,10, \\
$1.1{ }^{\circ} \mathrm{C}$ & $15 \mathrm{~W} / \mathrm{g})$ \\
Combined uncertainty & $4.06 / 4.03 / 4.02$ (for 5,10, \\
& $15 \mathrm{~W} / \mathrm{g})$ \\
\hline \hline
\end{tabular}

\section{CALIBRATION METHODS}

When subjecting a GT to transient heating conditions, it is in principle possible to infer its sensitivity. For instance, by preheating a GT to $100{ }^{\circ} \mathrm{C}$ (in boiling water) and then dipping it into ice-water (the so-called dip-test), the decay constant can be used to deduce the GT sensitivity by making use of an analytical model. Another transient heating method consists in heating the thermocouple by sending an ac current through it, stop the heating and record the decaying temperature of the inner body (while keeping the outside of the GT at a fixed temperature).

The relation between the time constant $(\tau)$ and the sensitivity $(\mathrm{S})$ is given by:

$S=\frac{\left\lfloor 1-\frac{1}{\cosh (\sqrt{A} L)}\right\rfloor}{A \cdot k_{b}} \cdot \rho$

in which

$A=\frac{C_{v} \cdot \rho}{\tau \cdot k_{b}}-\left[\frac{\pi}{2 \cdot L}\right]^{2}$

where $C_{v}, \rho, \mathrm{k}_{\mathrm{b}}$ and $\mathrm{L}$ are respectively the specific heat, the density, the thermal conductivity and the length of the inner body. In order to arrive at this analytical relation, one has to assume that the thermal material parameters do not vary over the GT, while in general some variations exist because of the non-uniform temperature. In addition, the obtained relation will only be valid at the average temperature during the test.

Since we have however a detailed finite element model of the GT, one can use this model to calculate the time constant and compare it to the experimental value. If both are in good agreement, one can then safely assume that the calculated sensitivity of the GT is correct. In addition, one can then also 
assume that the calculated sensitivities for other environment temperatures are correct.

\section{MINIATURE GAMMA THERMOMETER}

The GT can be miniaturized even further by omitting completely the inner body and by using only the thermocouple as the gamma absorption medium (see Fig. 3).

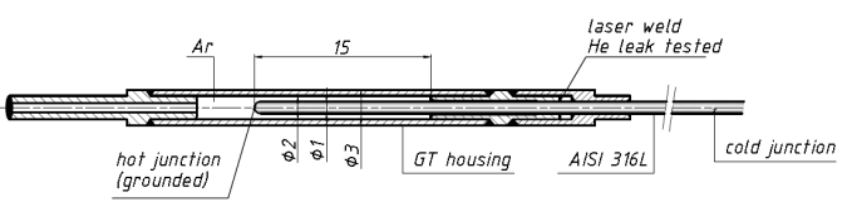

Fig. 3. Miniaturized GT, in which the inner body is reduced to only the thermocouple.

This has the advantages that the outer diameter of the GT can be reduced down to $3 \mathrm{~mm}$ and that the GT is easier to fabricate. Such a miniaturized GT, filled with argon has also been modelled by finite element calculations. The resulting sensitivity is about $14.4{ }^{\circ} \mathrm{C} /(\mathrm{W} / \mathrm{g})$. The calculated time constant is $9.09 \mathrm{~s}$.

A disadvantage of this design is that the uncertainties related to the material properties of the thermocouple (TC) have now a larger impact on the calculated sensitivities. One could remedy the situation by performing the dip-test or the electrical heating transient method, described earlier. For this type of GT one could also use a more direct calibration method: 1) Heat the TC by sending an ac current through it and 2) measure the temperature just after switching off the current. By relating the locally deposited power to the temperature increase, one obtains the sensitivity.

In case one sends a current of $0.5 \mathrm{~A}$ through the $\mathrm{TC}$, one obtains an equivalent gamma heat of $1.76 \mathrm{~W} / \mathrm{g}$, as compared to only $0.31 \mathrm{~W} / \mathrm{g}$ for the standard GT. A further improvement can be obtained by using a grounded (differential TC). In this case one could induce a higher current through each TC wire separately towards the sheath. When using a current of $1 \mathrm{~A}$ (through both wires), one obtains an equivalent gamma heating of $7.04 \mathrm{~W} / \mathrm{g}$. Thus in this case, one obtains a calibration point at a sufficiently high equivalent gamma heat (for the range $0-20 \mathrm{~W} / \mathrm{g}$ ). Another advantage of using the grounded TC is that the heating is applied up to the very end of the TC cable. In the case of an ungrounded TC, the hot junction is still 1 to $2 \mathrm{~mm}$ away from the end of the TC cable and then this part is not heated and the heat distribution in this case does not correspond to the case of gamma heating which occurs over the full length of the TC and inner body. Also, for the ungrounded TC, an additional fast decay of the temperature is observed just after switching off the current related to the thermal insulation of the TC wires by the
$\mathrm{Al}_{2} \mathrm{O}_{3}$ powder within the TC and this makes the direct electric calibration problematic in this case.

\section{GAMMA THERMOMETER WITH DIFFERENT ABSORPTION MATERIALS}

In order to determine the gamma heating in other materials, the inner body can be made for instance in tungsten, molybdenum or rhodium.

The responses of GTs with an inner body (diameter $2 \mathrm{~mm}$ ) made of tungsten, molybdenum and rhodium are shown in Fig. 4. It can be seen that the response of the tungsten GT is fairly linear over the range zero to $20 \mathrm{~W} / \mathrm{g}$. In fact, the curve is bending slightly upwards. This is a consequence of the fact that the thermal conductivity of tungsten is decreasing with increasing temperature. The responses of the Mo and Rh GTs are almost perfectly linear.

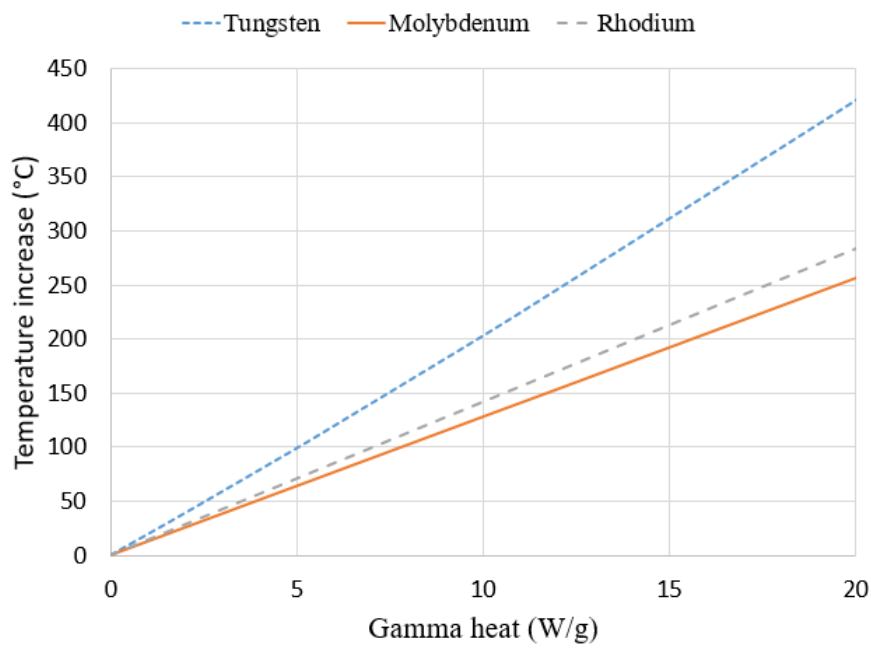

Fig. 4. Calculated temperature increase for an argon filled GT with an inner body made of tungsten, molybdenum and rhodium, at an outer temperature of $100^{\circ} \mathrm{C}$.

The calculated sensitivities and time constants are given in Table III.

TABLE III

OVERVIEW OF SENSITIVITIES (AT $100{ }^{\circ} \mathrm{C}$ ) AND TIME CONSTANTS FOR THE ARGON FILLED GTS FOR INNER BODIES MADE OF W, MO AND RH.

\begin{tabular}{llrr}
\hline \hline Material & Fill gas & $\begin{array}{r}\text { Sensitivity } \\
\left({ }^{\circ} \mathrm{C} /(\mathrm{W} / \mathrm{g})\right)\end{array}$ & $\begin{array}{r}\text { Time } \\
\text { constant }(\mathrm{s})\end{array}$ \\
\hline Tungsten & $\mathrm{Ar}$ & 20.8 & 2.84 \\
Molybdenum & $\mathrm{Ar}$ & 12.8 & 3.30 \\
Rhodium & $\mathrm{Ar}$ & 14.2 & 3.47 \\
AISI 304 & $\mathrm{Ar}$ & $35.8^{*}$ & 18.7 \\
AISI 304 & $\mathrm{He}$ & $10.0^{*}$ & 5.61 \\
\hline * At 1 W/g (nonlinear) & & &
\end{tabular}

The time constant of the GT with AISI 304 as inner body material and Ar fill gas was determined experimentally by the dip test method (from $100{ }^{\circ} \mathrm{C}$ to $0^{\circ} \mathrm{C}$ ) and was found to be 18.3 seconds, in good agreement with the theoretical value (18.7 s). 


\section{NEUTRON INDUCED HEATING}

When using a GT for gamma heating monitoring in a reactor core, neutrons will also lead to some heating. So in order to interpret the GT signal correctly, the relative heating contribution by neutrons should be assessed. We performed some preliminary MCNP calculations on the gamma and neutron heating in typical reactor conditions, for various materials of the inner body of the GT: graphite, Al, silicon nitride, AISI 304, Mo, Rh, Hf, W, Pb and $\mathrm{Bi}$.

The GT geometry was modeled using a set of infinitely long, concentric cylinders:

- $\quad r<0.55 \mathrm{~mm}$ : thermocouple (average thermocouple composition, mainly consisting of nickel and alumina, average density $5.885 \mathrm{~g} / \mathrm{cm}$ )

- $\quad 0.55 \mathrm{~mm}<\mathrm{r}<1.05 \mathrm{~mm}$ : inner body (various materials, with appropriate densities)

- $\quad 1.05 \mathrm{~mm}<\mathrm{r}<1.75 \mathrm{~mm}$ : gas volume; 10 bar nitrogen was taken as a gas in order to assess the maximum neutron heating in the gas (density $0.0125 \mathrm{~g} / \mathrm{cm}$ )

$1.75 \mathrm{~mm}<\mathrm{r}<2.25 \mathrm{~mm}$ : AISI304 sheath $(7.96 \mathrm{~g} / \mathrm{cm})$

A neutron (or gamma) source was defined on the outer surface of the sheath with a cosine direction distribution simulating an isotropic flux. Typical spectra for reflector channels in the BR2 research reactor were used. The total gamma flux was taken as $3.67 \cdot 10^{14} \mathrm{~V} /(\mathrm{cm} \mathrm{s})$; the neutron flux calculations were performed for two energy groups: $\mathrm{E}<5 \mathrm{eV}\left(1.19 \cdot 10^{14} \mathrm{n} /(\mathrm{cm} \mathrm{s})\right)$ and $\mathrm{E}>5 \mathrm{eV}\left(0.56 \cdot 10^{14} \mathrm{n} /(\mathrm{cm} \mathrm{s})\right)$.

For the pure gamma heating, F6:P tallies were used to get the heating per source gamma in each cell. For the neutron induced heating, coupled neutron-photon calculations were performed and the direct neutron heating rates were obtained from F6:N tallies, while $\mathrm{F} 6: \mathrm{P}$ yielded the heating rates via capture gammas. In the rhodium case, the neutron heating is strongly influenced by the energy deposition by betas emitted upon decay of ${ }^{104} \mathrm{Rh}$, formed after neutron capture by ${ }^{103} \mathrm{Rh}$. In this case a separate calculation approach was needed: calculation of the capture rates in rhodium, followed by an electron transport calculation to obtain the deposited beta energy in each cell. For the other materials, this contribution is much smaller and was not investigated in detail.

The results for the heating rates in the thermocouple + the inner body are summarized in Table IV (lower-Z materials) and Table $\mathrm{V}$ (higher-Z materials). As expected, the pure gamma heating rates expressed in $\mathrm{W} / \mathrm{g}$ increase monotonically with the atomic number $Z$. For most materials, the relative neutron heating contribution is rather small (3-10\%). In $\mathrm{SiN},(\mathrm{n}, \mathrm{p})$ reactions on ${ }^{14} \mathrm{~N}$ lead to a non-negligible neutron heating contribution. For Hf, the neutron induced heating contribution (via capture gammas) is significant. For Rh, the neutron induced heating (via decay betas) is even by far the dominant contribution. So a detector with $\mathrm{Rh}$ as inner body material could serve as a (thermal) neutron detector.
TABLE IV

CALCULATED HEATING RATES BY GAMMAS AND NEUTRONS IN THERMOCOUPLES + INNER PARTS FOR VARIOUS LIGHT MATERIALS. THE HEATING RATES ARE EXPRESSED IN W/CM OR IN W/G AS INDICATED. RELATIVE HEATING CONTRIBUTION DUE TO NEUTRONS IS SHOWN IN THE LAST LINE.

\begin{tabular}{llllll}
\hline \hline & $\mathrm{C}$ & $\mathrm{Al}$ & $\mathrm{SiN}$ & AISI304 & Mo \\
\hline $\mathrm{Z}$ & 6 & 13 & $7 / 14$ & $26 / 24 / 28$ & 42 \\
density $(\mathrm{g} / \mathrm{cm})$ & 2.23 & 2.7 & 3.17 & 7.96 & 10.2 \\
\hline $\mathrm{G}(\mathrm{W} / \mathrm{cm})$ & & & & & \\
pure $\mathrm{F}$ & 0.170 & 0.189 & 0.207 & 0.435 & 0.683 \\
pure n $(\mathrm{E}<5 \mathrm{eV})$ & 0.000 & 0.000 & 0.023 & 0.000 & 0.000 \\
pure n $(\mathrm{E}>5 \mathrm{eV})$ & 0.000 & 0.000 & 0.000 & 0.000 & 0.001 \\
n_(E $<5 \mathrm{eV}) \rightarrow \gamma$ & 0.008 & 0.010 & 0.010 & 0.035 & 0.040 \\
n_(E $>5 \mathrm{eV}) \rightarrow \gamma$ & 0.007 & 0.008 & 0.009 & 0.016 & 0.003 \\
$\mathrm{G}$ _total $(\mathrm{W} / \mathrm{cm})$ & 0.186 & 0.207 & 0.249 & 0.486 & 0.727 \\
\hline G_total $(\mathrm{W} / \mathrm{g})$ & 1.66 & 1.68 & 1.84 & 1.90 & 2.33 \\
\hline n-total $/$ total $(\%)$ & $8.4 \%$ & $8.6 \%$ & $16.8 \%$ & $10.5 \%$ & $6.1 \%$ \\
\hline \hline
\end{tabular}

TABLE V

Calculated heAting RAtes By Gammas AND NEUTRONS IN THERMOCOUPLES + INNER PARTS FOR VARIOUS HEAVY MATERIALS. THE HEATING RATES ARE EXPRESSED IN W/CM OR IN W/G AS INDICATED. RELATIVE HEATING CONTRIBUTION DUE TO NEUTRONS IS SHOWN IN THE LAST LINE.

\begin{tabular}{|c|c|c|c|c|c|}
\hline & $\mathrm{Rh}$ & Hf & $\mathrm{W}$ & $\mathrm{Pb}$ & $\mathrm{Bi}$ \\
\hline $\bar{Z}$ & 45 & 72 & 74 & 82 & 83 \\
\hline density $(\mathrm{g} / \mathrm{cm})$ & 12.4 & 13.31 & 19.35 & 11.34 & 9.8 \\
\hline \multicolumn{6}{|l|}{$\mathrm{G}(\mathrm{W} / \mathrm{cm})$} \\
\hline pure $\gamma$ & 0.823 & 1.181 & 1.566 & 1.163 & 1.089 \\
\hline pure n $(\mathrm{E}<5 \mathrm{eV})$ & 0.000 & 0.000 & 0.000 & 0.000 & 0.000 \\
\hline pure $n(E>5 e V)$ & 0.002 & 0.002 & 0.000 & 0.001 & 0.001 \\
\hline $\mathrm{n}_{-}(\mathrm{E}<5 \mathrm{eV}) \rightarrow \gamma$ & 0.611 & 0.477 & 0.125 & 0.037 & 0.033 \\
\hline $\mathrm{n} \_(\mathrm{E}>5 \mathrm{eV}) \rightarrow \gamma$ & 0.006 & 0.030 & 0.034 & 0.001 & 0.001 \\
\hline $\mathrm{n} \_(\mathrm{E}<5 \mathrm{eV}) \rightarrow \beta$ & 4.75 & & & & \\
\hline G_total $(\mathrm{W} / \mathrm{cm})$ & 6.187 & 1.689 & 1.725 & 1.202 & 1.124 \\
\hline G_total $(\mathrm{W} / \mathrm{g})$ & 16.85 & 4.33 & 3.19 & 3.53 & 3.72 \\
\hline n-total / total $(\%)$ & $86.7 \%$ & $30.1 \%$ & $9.2 \%$ & $3.2 \%$ & $3.1 \%$ \\
\hline
\end{tabular}

\section{CONCLUSION}

The sensitivity of the SCK $\bullet$ CEN type gamma thermometer has been calculated over the gamma heating range from zero to 20 $\mathrm{W} / \mathrm{g}$. Although the argon filled GT has a higher sensitivity than the helium filled GT, it's response is also more non-linear. The linearity of the helium filled GT was found to be better at $300{ }^{\circ} \mathrm{C}$ than at $100{ }^{\circ} \mathrm{C}$.

Based on detailed finite element calculations, an uncertainty analysis has been performed for the SCK •CEN type gamma thermometer, taking into account material and geometrical uncertainties, as well as the uncertainty related to the temperature measurement itself. Although the relative uncertainty depends on the actual gamma heating, one can say that the overall uncertainty remains below $5 \%$ (with the lowest uncertainty obtained at the highest gamma heating).

It is also possible to experimentally determine the time constant of the GT and fine tune the finite element model to obtain agreement between the experimental and the theoretical values. Further, it is also possible to obtain a more direct calibration by establishing a relation between the temperature of the inner 
body and the electrical power delivered to the thermocouple (by sending a current through the thermocouple).

A novel type of GT has been proposed in which the inner heated body is reduced to the thermocouple itself. This GT has several advantages, such as reduced inner diameter (down to $3 \mathrm{~mm}$ ) and even better possibilities for calibration by the electrical heating method.

In order to determine the gamma heating in other materials than stainless steel, different GTs have been considered and modelled in which the inner body is made of $\mathrm{W}$, Mo or Rh. Because the thermal conductivity of these materials decrease with increasing temperature, a compensation for the increasing thermal conductivity of the thermocouple with temperature is obtained resulting in a more linear response than the standard GT. For Mo and Rh, a very linear response was obtained up to a gamma heating of $20 \mathrm{~W} / \mathrm{g}$. Because of the high thermal conductivity of $\mathrm{W}, \mathrm{Mo}$ and $\mathrm{Rh}$, the time constants of these argon filled GTs were found to be rather small, namely below 4 seconds.

MCNP calculations were performed in order to assess the gamma and neutron heating contributions separately. The pure gamma heating rates expressed in $\mathrm{W} / \mathrm{g}$ increase monotonically with the atomic number $Z$. For most materials, the relative neutron heating contribution is rather small (3-10\%). In SiN and $\mathrm{Hf},(\mathrm{n}, \mathrm{p})$ and $(\mathrm{n}, \gamma)$ reactions lead to higher neutron induced heating contributions. For $\mathrm{Rh}$, the neutron induced heating (via decay betas) is even by far the dominant contribution. So a detector with $\mathrm{Rh}$ as inner body material could serve as a (thermal) neutron detector.

\section{REFERENCES}

1. O. Aarestad (1992, October), In-core Instrumentation for LWRs, Presented at IAEA meeting on "In-core Instrumentation and In-situ Measurements in Connection with Fuel Behaviour", held in Petten, The Netherlands, Available: https://inis.iaea.org/collection/NCLCollectionStore/_Public/28 /018/28018794.pdf

2. S. Solstad and R. Van Nieuwenhove (2011) Nuclear Technology, vol. 173, no 1, pp. 78-85, Jan. 2011. 